\title{
Radiation Dose to Technologists per Nuclear Medicine Examination and Estimation of Annual Dose
}

\author{
Tuncay Bayram ${ }^{1,2}$, A. Hakan Yilmaz ${ }^{2}$, Mustafa Demir ${ }^{3}$, and Bircan Sonmez ${ }^{4}$ \\ ${ }^{I}$ Department of Physics, Sinop University, Sinop, Turkey; ${ }^{2}$ Department of Physics, Karadeniz Technical University, Trabzon, Turkey; \\ ${ }^{3}$ Department of Nuclear Medicine, Cerrahpasa Faculty of Medicine, Istanbul University, Istanbul, Turkey; and ${ }^{4}$ Department of \\ Nuclear Medicine, Faculty of Medicine, Karadeniz, Technical University, Trabzon, Turkey
}

\begin{abstract}
Conventional diagnostic nuclear medicine applications have been continuously increasing in most nuclear medicine departments in Turkey, but to our knowledge no one has studied the doses to technologists who perform nuclear medicine procedures. Most nuclear medicine laboratories do not have separate control rooms for technologists, who are quite close to the patient during data acquisition. Technologists must therefore stay behind lead shields while performing their task if they are to reduce the radiation dose received. The aim of this study was to determine external radiation doses to technologists during nuclear medicine procedures with and without a lead shield.
\end{abstract} Another aim was to investigate the occupational annual external radiation doses to Turkish technologists. Methods: This study used a Geiger-Müller detector to measure dose rates to technologists at various distances from patients $(0.25,0.50,1$, and $2 \mathrm{~m}$ and behind a lead shield) and determined the average time spent by technologists at these distances. Deep-dose equivalents to technologists were obtained. The following conventional nuclear medicine procedures were considered: thyroid scintigraphy performed using ${ }^{99 m} \mathrm{Tc}$ pertechnetate, whole-body bone scanning performed using ${ }^{99 \mathrm{~m} T c-m e t h y l e n e}$ diphosphonate, myocardial perfusion scanning performed using $99 \mathrm{mTc}-$ methoxyisobutyl isonitrile, and ${ }^{201} \mathrm{Tl}$ (thallous chloride) and renal scanning performed using ${ }^{99 m}$ Tc-dimercaptosuccinic acid. Results: The measured deep-dose equivalent to technologists per procedure was within the range of $0.13 \pm 0.05$ to $0.43 \pm$ $0.17 \mu$ Sv using a lead shield and $0.21 \pm 0.07$ to $1.01 \pm 0.46 \mu \mathrm{Sv}$ without a lead shield. Also, the annual individual dose to a technologist performing only a particular scintigraphic procedure throughout a year was estimated. Conclusion: For a total of 95 clinical cases (71 patients), effective external radiation doses to technologists were found to be within the permissible levels. This study showed that a 2-mm lead shield markedly reduced the external dose to technologists. The doses to technologists varied significantly for different diagnostic applications. Consequently, the estimated annual dose to a technologist performing only a particular scintigraphic procedure is very different from one type of procedure to another. The results of this study

\footnotetext{
Received Jun. 17, 2010; revision accepted Oct. 1, 2010.

For correspondence or reprints contact: Tuncay Bayram, Karadeniz Technical University, Faculty of Science, Department of Physics, 61080, Trabzon, Turkey.

E-mail: tuncay42bayram@yahoo.com

COPYRIGHT @ 2011 by the Society of Nuclear Medicine, Inc.
}

should help in determining the rotation time of technologists in different procedures and differences in their individual techniques.

Key Words: radiation protection; occupational dose; nuclear medicine technologist; shielding

J Nucl Med Technol 2011; 39:55-59

DOI: 10.2967/jnmt.110.080358

$\mathbf{I}_{\mathrm{n}}$ diagnostic nuclear medicine, distribution and localization of the administered radiopharmaceutical provide functional or metabolic information. Patients and nuclear medicine workers are exposed to radiation doses from the tagged compounds administered to a patient for diagnostic purposes. Especially, technologists come into close proximity with radiation sources, receiving radiation doses while performing procedures such as preparing and administering the radioisotope, positioning the patient on the scanner bed, monitoring the patient during data acquisition, removing the patient from the bed, and escorting the patient to the department (1). In Turkey, all workers in nuclear medicine routinely use personal thermoluminescence dosimeters supplied by the Turkish Atomic Energy Authority.

Many investigators have measured the average external dose rates to technologists at various distances from patients and the average time that the technologist spends at specified distances from the patient $(2,3)$. Other investigators have used pocket electronic dosimeters to record the total dose per study $(2,4,5)$ or the total dose per day (6). Direct experimental determination of the external radiation dose to the nuclear medicine technologists per single procedure may follow 1 of 2 strategies. The first is based on accurate measurements of the dose rate at fixed distances from the patient and less accurate evaluations of the time spent by the operator at those distances. The second strategy consists of the direct reading of an electronic dosimeter worn by the technologist during the procedure. The first strategy yields a rough approximation of measurements of 
dose rate but is more general and allows a direct comparison of dose rates between different published data (2).

The first aim of this study was to determine dose rates with respect to distance from patients for the most common diagnostic procedures: thyroid scintigraphy performed

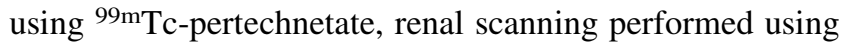
${ }^{99 m}$ Tc-dimercaptosuccinic acid (DMSA), whole-body bone scanning performed using ${ }^{99 \mathrm{~m}} \mathrm{Tc}-\mathrm{methylene}$ diphosphonate (MDP), and myocardial perfusion scanning performed using ${ }^{99 \mathrm{~m}}$ Tc-methoxyisobutyl isonitrile (MIBI) (stress + rest) and ${ }^{201} \mathrm{Tl}$ (thallous chloride) (stress + redistribution). The second aim was to estimate the average external dose to technologists from each of these diagnostic procedures with and without a lead shield using the measured dose rates. The third aim was to determine the dose to technologists from patient positioning and from patient monitoring with and without a lead shield for these diagnostic procedures. The last aim was to determine the annual dose to technologists performing a single type of procedure throughout the year.

\section{MATERIALS AND METHODS}

Previous studies have demonstrated that the external ionizing radiation exposure of nuclear medicine technologists arises primarily from radioactive patients rather than from the preparation and injection of radiopharmaceuticals (4). Therefore, we focused on the deep-dose equivalent to technologists. Eight technologists with more than $5 \mathrm{y}$ of experience in general nuclear medicine were instructed to spend as little time near the patient as possible. In Cerrahpasa Nuclear Medicine Laboratory, there were 2 technologists responsible for performing the ${ }^{99 \mathrm{~m}}$ Tc-MDP whole-body bone scans, ${ }^{99 \mathrm{~m}}$ Tc-DMSA renal scans, and ${ }^{99 m}$ Tc-pertechnetate thyroid scans considered in this work. Also, 2 technologists were responsible for both 99m Tc-MIBI and ${ }^{201} \mathrm{Tl}$ myocardial perfusion scans throughout the year. Each of the 2 technologists responsible for a particular procedure performed the same number of diagnostic procedures in a day and did not participate in any other diagnostic procedures. Each of the 2 technologists performed the same procedure. The patients who participated in this study were selected randomly.

Radiation doses to technologists were estimated by measuring the time interval and dose rate at various distances $(0.25,0.50,1.0$, and $2 \mathrm{~m})$ from the patient, with and without a $2-\mathrm{mm}$ lead shield. During data acquisition, the lead shield was $1 \mathrm{~m}$ from the patient and technologist for all measurements. In these measurements, the distance of the technologist from the patient was about $25 \mathrm{~cm}$ during patient positioning on the scanner bed. In some cases, patients positioned themselves after receiving instructions. The technologists stood on a mark $(0.5$ or $1 \mathrm{~m}$ from the scanner bed) while they were speaking with patients about the procedure. Operators carefully measured the mean time spent by technologists at these distances and, using a portable Geiger-Müller detector (Eberline Smart Portable 2 ) in rate meter operating mode after patient positioning, measured the dose rates at these distances. By regulation, the Turkish Atomic Energy Authority mandates annual calibration of the exposure rate of portable radiation monitoring instruments in Turkey. Therefore, this detector was calibrated by the Turkish Atomic Energy Authority. Moreover, the detector was tested with a point source of ${ }^{99 \mathrm{~m}} \mathrm{Tc}$ and ${ }^{201} \mathrm{Tl}$. In this test, the relative SD on the measurements was $9.65 \%$ and $9.94 \%$ for ${ }^{99 \mathrm{~m}} \mathrm{Tc}$ and ${ }^{201} \mathrm{Tl}$, respectively. These relative SDs were considered in calculations.

In all, 71 patients were measured, for a total of fortyeight ${ }^{99 \mathrm{~m}} \mathrm{Tc}-\mathrm{MIBI}$ and ${ }^{201} \mathrm{Tl}$ myocardial perfusion scans (stress + rest), twenty ${ }^{99 m}$ Tc-MDP whole-body bone scans, twelve ${ }^{99 \mathrm{~m}}$ Tc-pertechnetate thyroid scans, and fifteen ${ }^{99 m}$ Tc-DMSA renal scans.

The measurements were obtained as $\mathrm{mR} / \mathrm{h}$ using the Geiger-Müller detector and were converted to $\mu \mathrm{Sv} / \mathrm{h}$ using the equation $\mathrm{mR} / \mathrm{h}=10 \mu \mathrm{Sv} / \mathrm{h}$. Because the selected unit of time was seconds, the equation $\mathrm{mR} / \mathrm{h}=(10 / 3,600) \mu \mathrm{Sv} / \mathrm{s}$ was used. Time (seconds) and relative dose rates were multiplied by each other. Finally, mean external doses to technologists and their SDs for 3 scenarios were calculated. These were the doses to technologists arising from positioning patients and the total doses to technicians aris-

TABLE 1

External Dose Rates per Procedure Measured at Various Distances from Patient

\begin{tabular}{|c|c|c|c|c|}
\hline \multicolumn{5}{|c|}{ Distance from patient } \\
\hline Type of examination & $0.25 \mathrm{~m}$ & $0.5 \mathrm{~m}$ & $1 \mathrm{~m}$ & $2 \mathrm{~m}$ \\
\hline Whole-body bone scan ( $\left.{ }^{99 m} \mathrm{Tc}-\mathrm{MDP}\right)$ & $1.31 \pm 0.71$ & $0.56 \pm 0.20$ & $0.33 \pm 0.12$ & $0.13 \pm 0.03$ \\
\hline Thyroid scan (99mTc-pertechnetate) & $1.70 \pm 0.73$ & $0.86 \pm 0.23$ & $0.43 \pm 0.09$ & $0.20 \pm 0.02$ \\
\hline Renal scan ( ${ }^{99 m}$ Tc-DMSA) & $1.06 \pm 1.13$ & $0.48 \pm 0.36$ & $0.24 \pm 0.16$ & $0.08 \pm 0.02$ \\
\hline \multicolumn{5}{|l|}{ Myocardial perfusion scan } \\
\hline 99mTc-MIBI, stress & $1.65 \pm 1.04$ & $0.69 \pm 0.26$ & $0.27 \pm 0.13$ & $0.09 \pm 0.03$ \\
\hline 99mTc-MIBI, rest & $2.29 \pm 1.35$ & $1.42 \pm 0.59$ & $0.43 \pm 0.18$ & $0.19 \pm 0.06$ \\
\hline${ }^{201} \mathrm{Tl}$-chloride, stress & $0.32 \pm 0.16$ & $0.13 \pm 0.03$ & $0.07 \pm 0.05$ & $0.03 \pm 0.01$ \\
\hline${ }^{201} \mathrm{Tl}$-chloride, redistribution & $0.34 \pm 0.16$ & $0.18 \pm 0.06$ & $0.13 \pm 0.08$ & $0.05 \pm 0.01$ \\
\hline
\end{tabular}

Data are mean $\pm S D(m R / h)$. 
TABLE 2

Dose to Technologists per Nuclear Medicine Examination in Different Diagnostic Applications

\begin{tabular}{|c|c|c|c|c|}
\hline Type of examination & $n$ & $\begin{array}{c}\text { Patient } \\
\text { positioning dose }\end{array}$ & $\begin{array}{l}\text { Total dose using } \\
\text { lead shield }\end{array}$ & $\begin{array}{c}\text { Total dose without } \\
\text { lead shield }\end{array}$ \\
\hline Whole-body bone scan ( $\left.{ }^{99 m} \mathrm{Tc}-\mathrm{MDP}\right)$ & 20 & $0.10 \pm 0.05$ & $0.24 \pm 0.08$ & $0.57 \pm 0.15$ \\
\hline Thyroid scan ( ${ }^{99 m}$ Tc-pertechnetate) & 12 & $0.08 \pm 0.03$ & $0.15 \pm 0.02$ & $0.26 \pm 0.06$ \\
\hline Renal scan ( ${ }^{99 m}$ Tc-DMSA) & 15 & $0.03 \pm 0.03$ & $0.13 \pm 0.05$ & $0.21 \pm 0.07$ \\
\hline \multicolumn{5}{|l|}{ Myocardial perfusion scan } \\
\hline 99mTc-MIBI & $28^{*}$ & $0.13 \pm 0.08$ & $0.43 \pm 0.17$ & $1.01 \pm 0.46$ \\
\hline${ }^{201}$ Tl-chloride & $20^{\dagger}$ & $0.02 \pm 0.01$ & $0.16 \pm 0.04$ & $0.23 \pm 0.08$ \\
\hline $\begin{array}{l}{ }^{\star} \text { Stress }+ \text { rest. } \\
{ }^{\dagger} \text { Stress }+ \text { redistribution. } \\
\text { Data are mean } \pm \mathrm{SD}(\mu \mathrm{Sv})\end{array}$ & & & & \\
\hline
\end{tabular}

ing from diagnostic procedures both with and without lead shields.

For ${ }^{99 \mathrm{~m}} \mathrm{Tc}$-pertechnetate thyroid scans, the patients were imaged using a $\gamma$-camera after the intravenous injection of $75-370 \mathrm{MBq}(2-10 \mathrm{mCi})$ of ${ }^{99 \mathrm{~m}} \mathrm{Tc}-$ pertechnate. Imaging began 15-30 min after the injection.

For ${ }^{99 \mathrm{~m}} \mathrm{Tc}-\mathrm{MDP}$ whole-body bone scans, the patients were imaged 2-3 h after the intravenous injection of 740 $\mathrm{MBq}(20 \mathrm{mCi})$ of ${ }^{99 \mathrm{~m}} \mathrm{Tc}-\mathrm{MDP}$. Standard anterior and posterior whole-body images were obtained on a dual-head planar $\gamma$-camera.

The procedure for myocardial perfusion scanning with ${ }^{99 m}$ Tc-MIBI had 2 stages. The first involved stress imaging after injection of $555 \mathrm{MBq}-1.11 \mathrm{GBq}(15-30 \mathrm{mCi})$ of ${ }^{99 \mathrm{~m} T c-M I B I}$ at peak exercise. Gated SPECT was performed from 15 min to $2 \mathrm{~h}$ after the injection, preferably within 15$30 \mathrm{~min}$. The second stage involved rest imaging after administration of $555 \mathrm{MBq}-1.11 \mathrm{GBq}(15-30 \mathrm{mCi})$ of 99mTc-MIBI. Gated SPECT was performed within 45$60 \mathrm{~min}$ after the injection.

Likewise, the procedure for myocardial perfusion scanning with ${ }^{201}$ Tl-chloride had 2 stages. The first involved stress imaging after injection of $148 \mathrm{MBq}(4 \mathrm{mCi})$ of ${ }^{201} \mathrm{Tl}$ at peak exercise. Imaging began within 5-7 min after the injection. The second stage, redistribution imaging, involved administering $37-55.5 \mathrm{MBq}(1.0-1.5 \mathrm{mCi})$ of ${ }^{201} \mathrm{Tl}$ and imaging $3-4 \mathrm{~h}$ after the first injection.
For ${ }^{99 \mathrm{~m}} \mathrm{Tc}-\mathrm{DMSA}$ renal scanning, the administered activity was $185 \mathrm{MBq}(5 \mathrm{mCi})$ for adults. In most cases, imaging could be performed $1-3 \mathrm{~h}$ after the injection.

\section{RESULTS}

Some studies have listed the dose to technologists from injecting patients $(1,4)$. Our study did not measure this dose because, in Turkey, the injection is almost always administered by a nurse, not a technologist.

Table 1 shows mean external dose rates measured at various distances from the patient for whole-body bone scans, renal scans, thyroid scans, and myocardial perfusion scans. The external dose rates can be seen to diminish as distance from the patient increases.

The main results are summarized in Table 2, which shows the patient positioning dose and total dose (including patient positioning dose) to technologists with and without a lead shield. ${ }^{99 \mathrm{~m} T c-M I B I}$ myocardial perfusion scans imparted higher doses $(1.01 \pm 0.46 \mu \mathrm{Sv}$ without a lead shield and $0.43 \pm 0.17 \mu \mathrm{Sv}$ with a lead shield) to technologists than did the other types of scans. Although ${ }^{201} \mathrm{Tl}$ myocardial perfusion scans were applied in the same manner as ${ }^{99 \mathrm{~m} T c-M I B I},{ }^{201} \mathrm{Tl}$ yielded lower doses to technologists $(0.23 \pm 0.08 \mu \mathrm{Sv}$ without a lead shield and $0.16 \pm$ $0.04 \mu \mathrm{Sv}$ with a lead shield). The contributions of the patient positioning dose to total dose (without a lead shield) were approximately $18 \%, 31 \%, 14 \%, 13 \%$, and $9 \%$ for

TABLE 3

Estimated Annual Total Doses to Technologists Responsible for a Particular Diagnostic Procedure

\begin{tabular}{lcc}
\hline \multicolumn{1}{c}{ Type of examination } & $\begin{array}{c}\text { Mean annual dose } \\
\text { using lead shield }\end{array}$ & $\begin{array}{c}\text { Mean annual dose } \\
\text { without lead shield }\end{array}$ \\
\hline Whole-body bone scan (99mTc-MDP) & 1.50 & 3.56 \\
Thyroid scan (99mTc-pertechnetate) & 0.94 & 1.63 \\
Renal scan (99mTc-DMSA) & 0.33 & 0.53 \\
Myocardial perfusion scan & & 0.86 \\
99mTc-MIBI & 0.20 & 2.02 \\
201TI-chloride & & 0.29
\end{tabular}

Data are in millisieverts. 
TABLE 4

Annual Doses to Technologists as Measured with Thermoluminescence Dosimeters

\begin{tabular}{|c|c|c|c|}
\hline Type of examination & $\begin{array}{l}\text { Annual dose to } \\
\text { technologist } 1\end{array}$ & $\begin{array}{l}\text { Annual dose to } \\
\text { technologist } 2\end{array}$ & Annual mean dose \\
\hline Whole-body bone scan (99mTc-MDP) & 4.05 & 3.65 & 3.85 \\
\hline Thyroid scan ( ${ }^{99 m T c-p e r t e c h n e t a t e) ~}$ & 1.72 & 1.40 & 1.56 \\
\hline Renal scan (99mTc-DMSA) & 1.35 & 1.52 & 1.44 \\
\hline Myocardial perfusion scan (99mTc-MIBI + ${ }^{201} \mathrm{TI}-$ chloride) & 3.99 & 4.25 & 4.12 \\
\hline
\end{tabular}

${ }^{99 m}$ Tc-MDP whole-body bone scans, ${ }^{99 m}$ Tc-pertechnetate thyroid scans, ${ }^{99 \mathrm{~m}}$ Tc-DMSA renal scans, ${ }^{99 \mathrm{~m}} \mathrm{Tc}-\mathrm{MIBI}$ myocardial perfusion scans, and ${ }^{201} \mathrm{Tl}$ myocardial perfusion scans, respectively.

The annual total dose to a technologist responsible for only a particular diagnostic procedure throughout the year was determined using the values in Table 2 and the annual numbers of cases in the nuclear medicine laboratory: $6,236,6,286,2,510,1,996$, and 1,261 for ${ }^{99 m}$ Tc-MDP whole-body bone scans, ${ }^{99 \mathrm{~m}} \mathrm{Tc}$-pertechnetate thyroid scans, ${ }^{99 \mathrm{~m}}$ Tc-DMSA renal scans, ${ }^{99 \mathrm{~m}}$ Tc-MIBI myocardial perfusion scans, and ${ }^{201} \mathrm{Tl}$ myocardial perfusion scans, respectively. Table 3 shows the estimated total annual doses to technologists who work with and without a lead shield.

Table 4 shows the annual doses to 8 technologists, as measured using personal thermoluminescence dosimeters. The annual doses to technologists responsible for the same diagnostic procedure throughout the year were close to one another. Differences in individual techniques among the technologists seemed to be small.

\section{DISCUSSION}

In this study, the measured mean dose to technologists from all 4 procedures ranged from $0.13 \pm 0.05$ to $0.43 \pm$ $0.17 \mu \mathrm{Sv}$ with a lead shield and $0.21 \pm 0.07$ to $1.01 \pm 0.46$ $\mu \mathrm{Sv}$ without a lead shield. The values in Table 2 indicate that the use of a lead shield while performing nuclear medicine procedures significantly decreased the dose to technologists. For ${ }^{99 m}$ Tc-MDP whole-body bone scans, 99m Tc-pertechnetate thyroid scans, ${ }^{99 m}$ Tc-DMSA renal scans, ${ }^{99 \mathrm{~m} T c-M I B I}$ myocardial perfusion scans, and ${ }^{201} \mathrm{Tl}$ myocardial perfusion scans, the dose to the technologist was $2.37,1.73,1.61,2.35$, and 1.45 times higher, respectively, when a $2-\mathrm{mm}$ lead shield was not used than when it was used. If a lead shield thicker than $2 \mathrm{~mm}$ were to be used, the dose could be lowered even further.

The values in Tables 3 and 4 indicate that even without a rotation of the work force, and even with a major increase in the number of patients, the annual dose to individual technologists would not reach the annual limit $(20 \mathrm{mSv})$ specified by the International Commission on Radiological Protection.
FIGURE 1. Doses to technologists per nuclear medicine procedure, in comparison with study of Chiesa et al. (2).

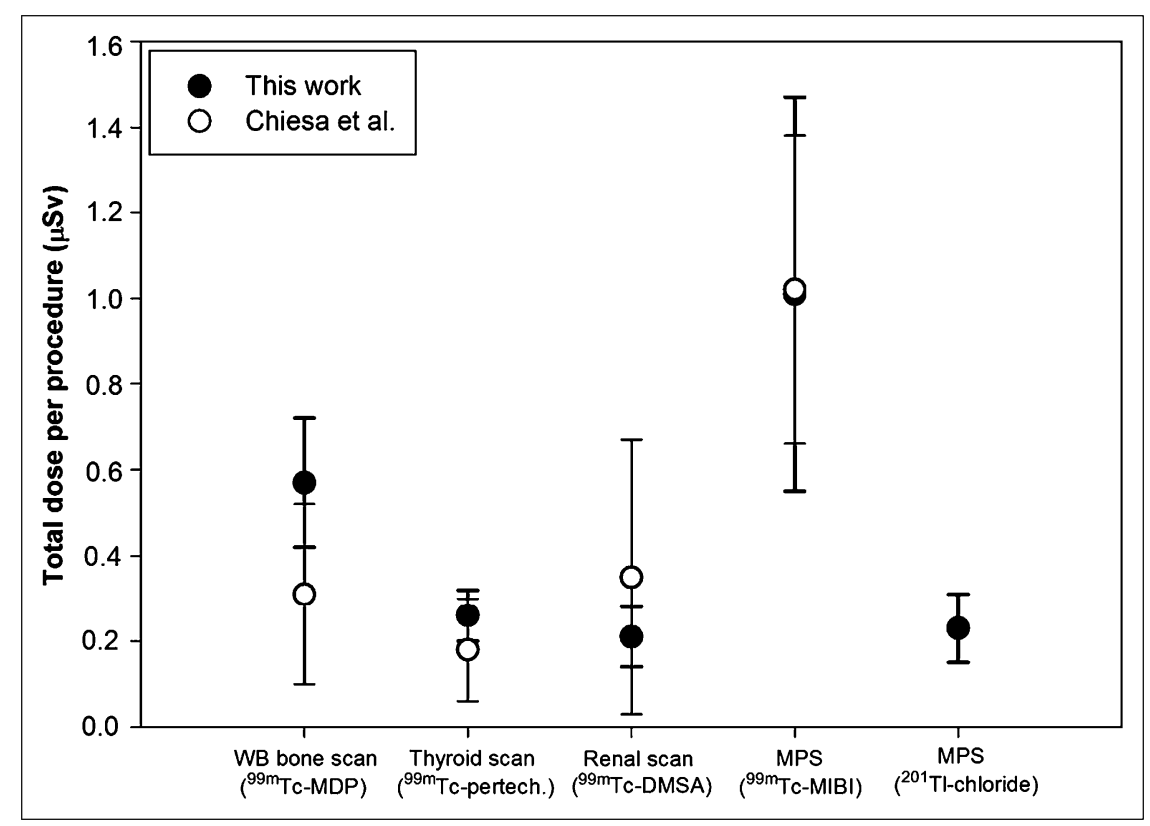


Annual doses as indicated by thermoluminescence dosimeters agreed with the estimated mean annual doses for ${ }^{99 \mathrm{~m}} \mathrm{Tc}-$ MDP whole-body bone scans and ${ }^{99 \mathrm{~m}}$ Tc-pertechnetate thyroid scans but not for renal scans and myocardial perfusion scans. With regard to the myocardial perfusion scans, the lack of agreement may have occurred because technologists administered radiopharmaceuticals to patients during these scans but our study did not measure the dose to technologists from injecting radiopharmaceuticals. The doses may therefore have appeared lower than they really were.

Background corrections were applied in this study, and the error reported was only relative to the SD of measured doses. However, the high SDs were due to several variables: differences in the injected activity, in time between examination and injection, in the technologist, and in the biologic uptake of patients. These variables can cause different doses for the same procedures performed in different nuclear medicine laboratories. Generally, our results were close to those of Chiesa et al. (2). Figure 1 compares our results and those of Chiesa et al. with regard to doses to technologists per procedure. The doses reported by Chiesa et al. were mean doses per procedure for 2 technologists. SD was high in both studies. Also, there was a large difference for ${ }^{99 \mathrm{~m}}$ Tc-MDP whole-body bone scan doses. This could have arisen from the number of spot images after whole-body imaging considered in our study.

\section{CONCLUSION}

A 2-mm lead barrier reduced the dose to technologists by about 2 times for the common diagnostic procedures performed in this study. This result reemphasizes that tech- nologists should consider the use of shielding. Furthermore, this study found that external radiation doses to technologists were within permissible levels, regardless of whether a technologist performed only a particular diagnostic procedure. Therefore, rotation of technologists among different tasks is not necessary. Finally, the results of this study could be applied to the scheduling of scanning procedures by pregnant technologists to keep their fetal exposures as low as possible.

\section{ACKNOWLEDGMENTS}

We thank all the members of Istanbul University, Cerrahpasa Medicine Faculty Nuclear Medicine Department, for their sincere cooperation. We also thank Riza Isitan and Volkan Aylikci for their assistance with the language of the manuscript.

\section{REFERENCES}

1. Seierstad T, Stranden E, Bjering K, et al. Doses to nuclear technicians in a dedicated PET/CT centre utilising ${ }^{18} \mathrm{~F}$ fluorodeoxyglucose (FDG). Radiat Prot Dosimetry. 2007;123:246-249.

2. Chiesa C, De Sanctis V, Crippa F, et al. Radiation dose to technicians per nuclear medicine procedure: comparison between technetium-99m, gallium-67, and iodine-131 radiotracers and fluorine-18 fluorodeoxyglucose. Eur J Nucl Med. 1997;24:1380-1389.

3. Kurtaran A, Preitfellner J, Kohoutek D, Tousek A, Virgolini I, Havlik E. Radiation exposure in the surroundings of patients after ${ }^{201} \mathrm{Tl}$ myocardial scintigraphy [in German]. Nuklearmedizin. 1997;36:29-31.

4. Smart R. Task-specific monitoring of nuclear medicine technologists' radiation exposure. Radiat Prot Dosimetry. 2004;109:201-209.

5. Clarke EA, Thomson WH, Notghi A, Harding LK. Radiation doses from nuclear medicine patients to an imaging technologist: relation to ICRP recommendations for pregnant workers. Nucl Med Commun. 1992;13:795-798.

6. Lundberg TM, Gray PJ, Bartlett ML. Measuring and minimizing the radiation dose to nuclear medicine technologists. J Nucl Med Technol. 2002;30:25-30. 